\title{
Esophagus extirpation in the surgical treatment of neglected stages of esophageal achalasia
}

\author{
Feruz Gafurovich NAZIROV, Zaynitdin Mahamatovich NIZAMKHODJAYEV, Ruslan Efimovich LIGAY, \\ Aleksey Olegovich TSOI, Doniyor Bakhtiyarovich SHAGAZATOV, Elnar Ildarovich NIGMATULLIN ${ }^{\star 凶}$ \\ and Kudratbek Bahtiyarovich BABADJANOV
}

Republican Specialized Surgery Centre named after Academician V.Vakhidov, Tashkent city, Uzbekistan

Corresponding author's Email: rscs.elnar@gmail.com

\section{ABSTRACT}

Aim. The surgical treatment experience of patients with neglected stages of esophageal achalasia has been presented in the article. Methods. The esophagus extirpation with simultaneous gastroesophagoplasty due to esophageal achalasia of stage III-IV was performed in 28 patients. Results. The results of the research, identifies indications for surgical intervention, features of intra- and postoperative complications, immediate and long-term results of esophageal extirpation. Cardiodilation remains the main treatment method for patients with esophageal achalasia, but its efficiency is significantly reduced in patients with neglected stages. Conclusion. Esophagus extirpation in patients with neglected stages of achalasia is pathogenetically reasonable surgical intervention when there is severe esophagoectasia and S-shaped deformity of the esophagus and cardioesophageal junction. Further control randomized trials and multicentric studies should be performed.

\section{Original Article}

PII: S225199391900022-9

$\begin{array}{ll}\text { Rec. } & 11 \text { June } 2019 \\ \text { Rev. } & 23 \text { September } 2019 \\ \text { Pub. } & 25 \text { September } 2019\end{array}$

Keywords

Achalasia,

Neuromuscular diseases of the esophagus,

Esophageal extirpation, gastroplasty.

\section{INTRODUCTION}

Esophageal achalasia is one of the most common neuromuscular diseases of the esophagus at which the dystrophy of the Auerbach's plexus occurs. As a result, there is a disorder of the reflex of the cardia opening in response to a sip, the peristaltic activity of the esophagus is inhibited which leads to the development of severe esophagoectasia [1-4].

The etiopathogenesis of the disease still remains unclear. All treatment options are symptomatic and aimed at eliminating the main symptom - dysphagia. The main method of treatment is cardiodilation which is effective at any stages of the disease. However, in neglected cases, as well as in the recurrence of dysphagia, the effect of dilation is much less and surgical treatment is often necessary. There are more than 60 variants of surgical interventions for achalasia, most of which are numerous modifications of the Geller's operation. They are aimed to an extra-mucosal dissection of the distal esophagus and the stomach cardia muscles for reducing the gradient of the esophagogastric pressure, which facilitates the passage of the cardia [4-6]. However, in patients with achalasia the complete absence of the cardia opening in response to the sip and the complete absence of peristaltic activity of the esophagus wall, come to the fore. Therefore, in stage IV of the disease a good effect from cardioplastic operations cannot be expected.

The esophagus extirpation remains one of the most complicated operations in thoraco-abdominal surgery which is characterized by trauma, duration, high risk of intraoperative and postoperative complications. In most cases it is performed at esophageal cancer. The main advantage of esophagus extirpation is a complete removal of the pathologically changed organ - the esophagus. There are isolated reports in the world literature on the experience of using the extirpation of the esophagus in patients with achalasia of the cardia, which can be considered the only radical method of surgical treatment of this category of patients [1-4, 7]. 
This study aimed to investigate the esophagus extirpation results in the surgical treatment of neglected stages of esophageal achalasia.

\section{MATERIALS AND METHODS}

\section{Ethical approval}

The review board and ethics committee of Republican Specialized Surgery Centre named after Academician V.Vakhidov approved the study protocol and informed consents were taken from all the participants.

Total of 28 esophagus extirpations due to the neglected stages of achalasia were performed at the Department of Esophagus and Stomach Surgery of the Republican Specialized Scientific and Practical Medical Center of Surgery from 1998 to 2018. There were 18 males (64.2\%) and 10 females (35.8\%) participated in the study. The age of patients ranged from 11 to 62 years. Achalasia of stage III was in 4 patients (14.3\%) and stage IV in 24 patients (85.7\%). When collecting anamnestic data it was determined that 2 patients (7.1\%) had previously undergone esophagogicardiomy, and 1 patient (3.6\%) had previously undergone esophago-cardiomyotomy. The rest of patients were performed repeated courses of cardiodilation. The disease duration in all patients was more than 5 years.

All patients were performed a comprehensive examination which included endoscopic, radiopaque investigations, as well as Modern methods of radiation diagnostics (MSCT). Characteristic features along with the clinical presentation were evident esophagoectasia, the absence of peristaltic activity of the esophagus muscular wall, S-shape deformity of esophagus and cardia. The X-ray pattern of patients with neglected stages of achalasia stage IV is presented in Figure 1.
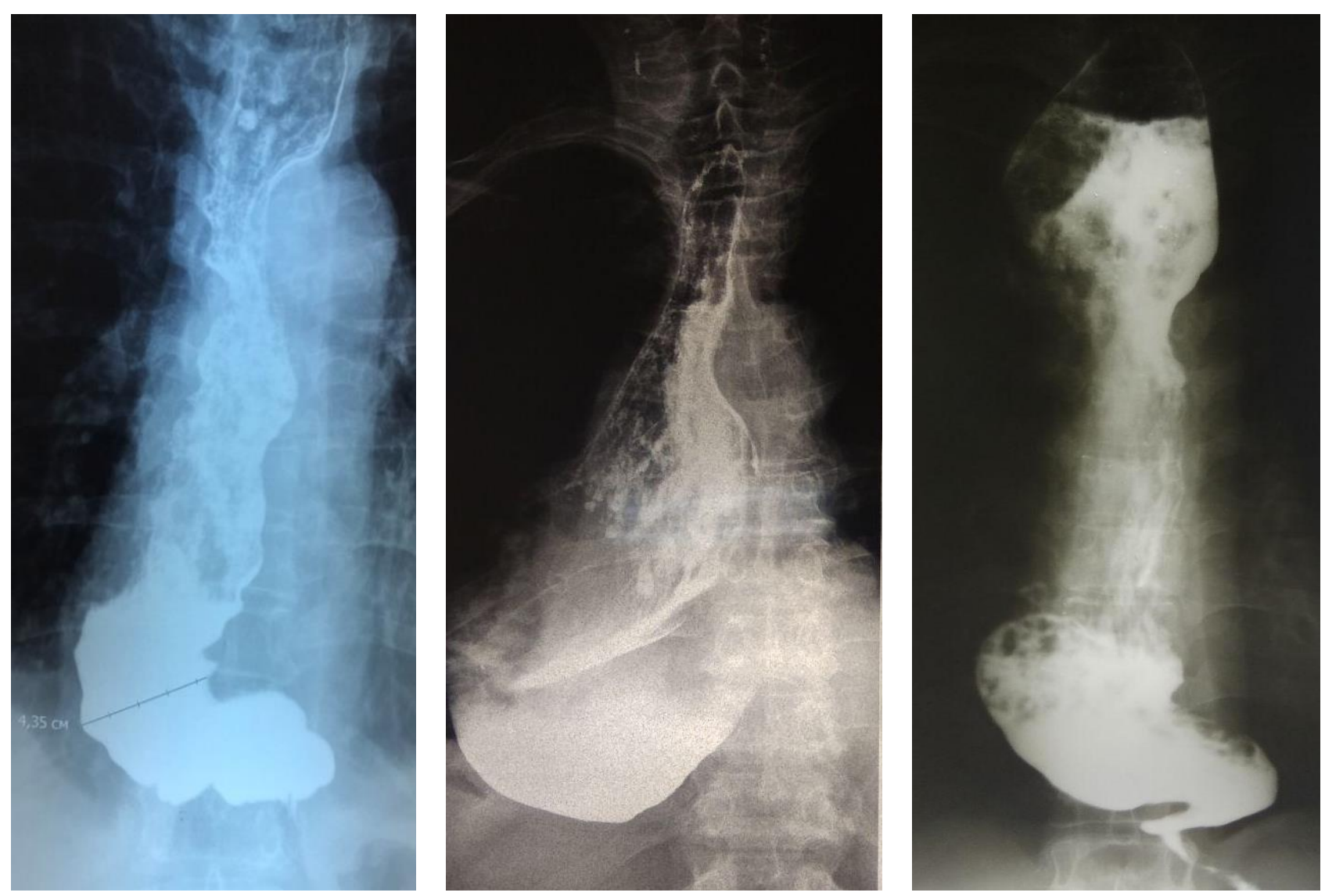

Figure 1. X-ray pattern of the esophagus (achalasia of stage IV)

Modern methods of radiation diagnostics (MSCT) allow not only to make a diagnosis, but also to determine the features of topographic-anatomical ratio of the esophagus to the rest of the structures of the mediastinum and pleural cavities (Figure 2). This is important when mobilizing the esophagus from the mediastinum through abdomino-cervical approach which is limited for visualization. 

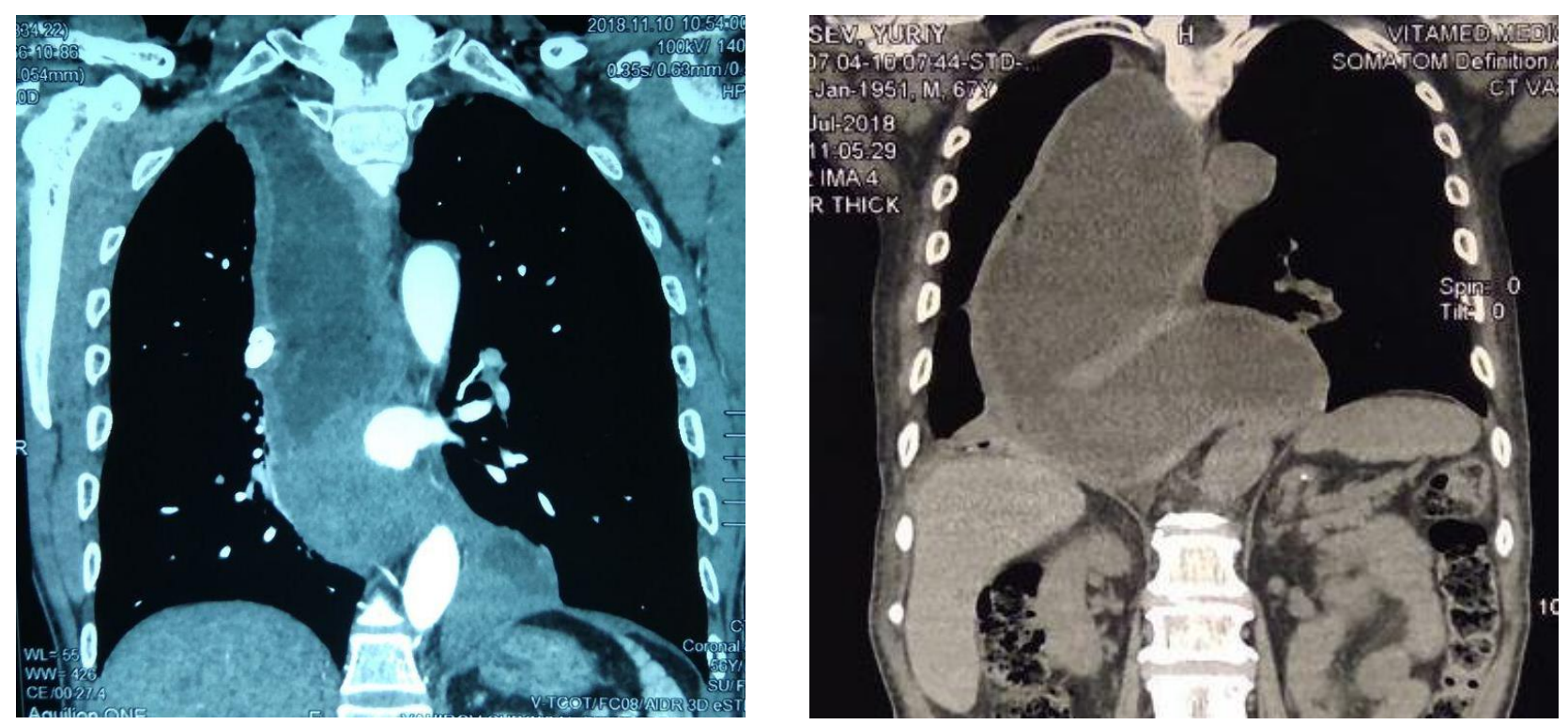

Figure 2. MSCT pattern of the esophagus (achalasia of stage IV)

\section{RESULTS}

The main methods of patients treatment with achalasia are various cardiodilation options (pneumatic, hydroballoon). However, in patients with neglected III-IV stages when there is S-shaped deformity, both of the esophagus and the stomach cardia, the possibilities of dilatation are sharply limited and the restoration of food patency is short. Such patients have to be performed surgical treatment. Indications for the esophagus extirpation in our patients were:

- Dilatation inefficiency, i.e. directly unsatisfactory result when after repeated (5-7) sessions patients did not have a clinical effect - in 8 cases (28.6\%);

- The impossibility of holding the dilator in the stomach which was evaluated on the basis of a comprehensive examination and was confirmed when trying to hold the dilator, when the risk of the esophagus injury exceeded the expected clinical effect - in 17 cases (60.7\%);

- Stenotic reflux esophagitis of the lower third of the thoracic esophagus against the background of previously performed esophagocardiomyotomy - in 3 cases (10.7\%).

There are 5 main factors in solving the issue of using esophageal extirpation in patients with neglected stages of achalasia:

1. Simultaneous performance of esophagoplasty. In all 28 cases the resection and recovery stage (esophagoplasty) were performed in one stage.

2. The choice of surgical approach. Abdomino-cervical approach was used in 27 patients (96.4\%) and thoraco-abdomino-cervical approach was performed in 1 case (3.6\%) because of the presence of concomitant pathology (echinococcosis of the middle lobe of the right lung) a simultaneous echinococcectomy from the lung was performed. The choice of the surgical approach nature was based on the fact that achalasia is a benign disease and does not require extensive lymphadenectomy, as the esophageal cancer, and therefore it is not advisable to use traumatic thoracic approach.

3. Volume of the esophagus resection (extirpation or resection). In patients with neglected stages of achalasia, esophagoectasia of all parts of the esophagus is noted due to dystrophy of the Auerbach's plexus. In the presence of indications for radical surgery it is necessary to remove almost the entire esophagus. Therefore, in all cases we performed the extirpation of the esophagus while leaving only a part of the cervical esophagus (3-4 cm) which was enough to form an anastomosis on the neck.

4. Method of esophagoplasty. When choosing the method of esophagoplasty, we preferred the use of an isoperistaltic gastric tube from the greater curvature of the stomach which was used in 24 patients. Only in 4 patients we used the left half of the colon to create a transplant due to the impossibility of gastroplasty.

5. Level of esophageal anastomosis application (intrapleural or extracavitary cervical). The solution of this issue is debatable only in patients with esophageal cancer. In all cases a cervical extracavitary esophageal anastomosis was formed in patients with achalasia.

The stages of the esophagus extirpation with gastroplasty have been shown in figure 3 . 


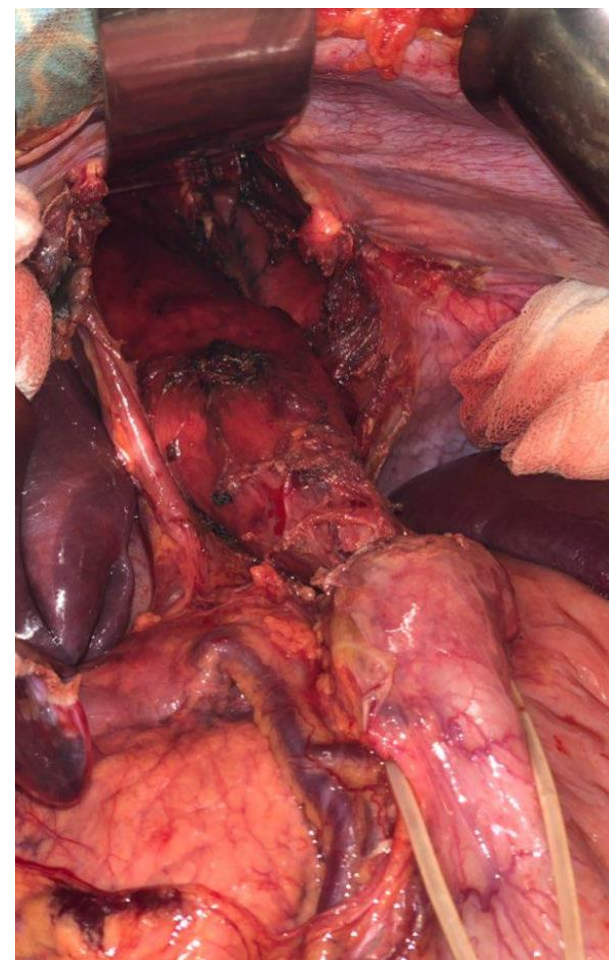

A

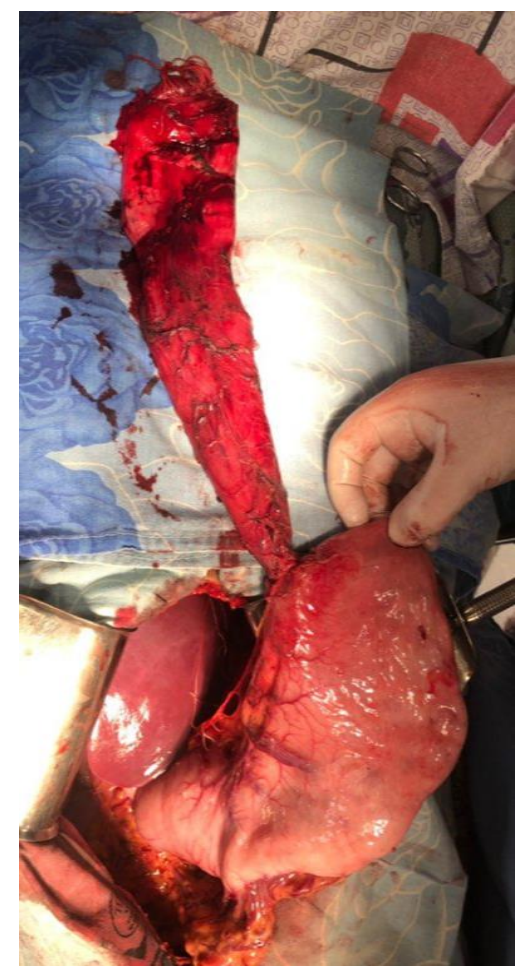

B

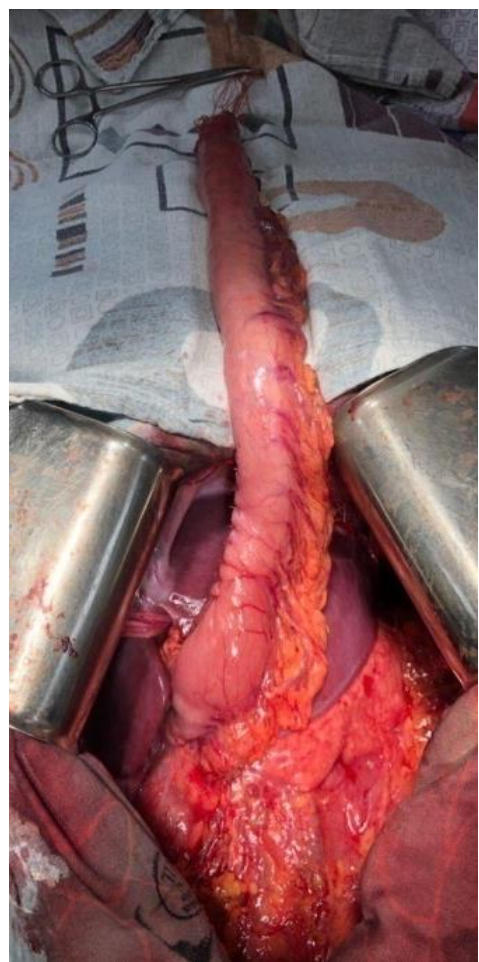

C

Figure 3. The stages of the esophagus extirpation with gastroplasty. $A=$ Mobilization of the esophagus after diaphragmotomy. $\mathrm{B}=$ The extracted esophagus with mobilized stomach. $\mathrm{C}=$ The formed gastrotransplant

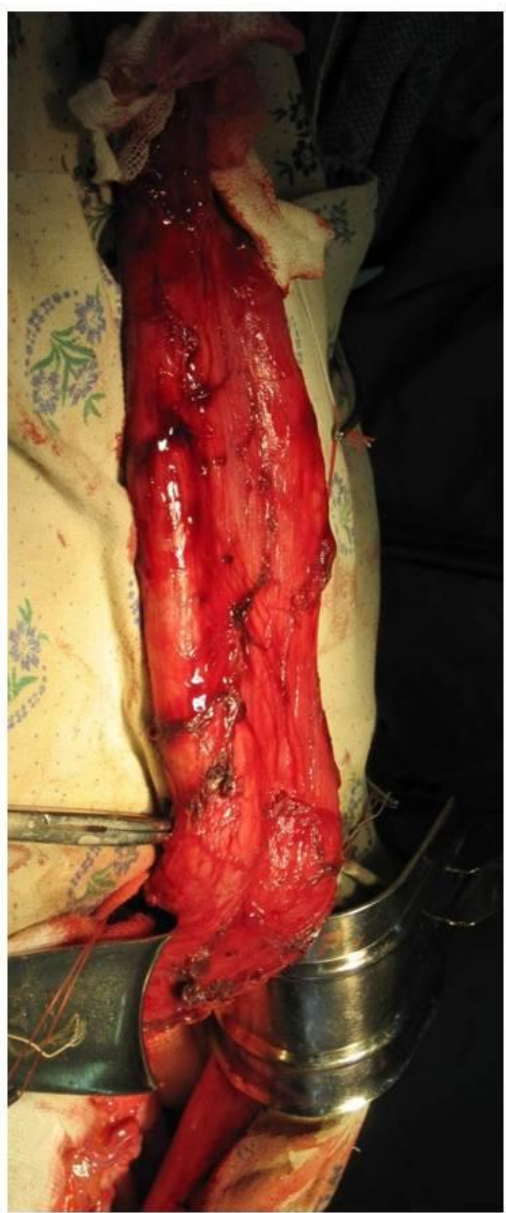

A

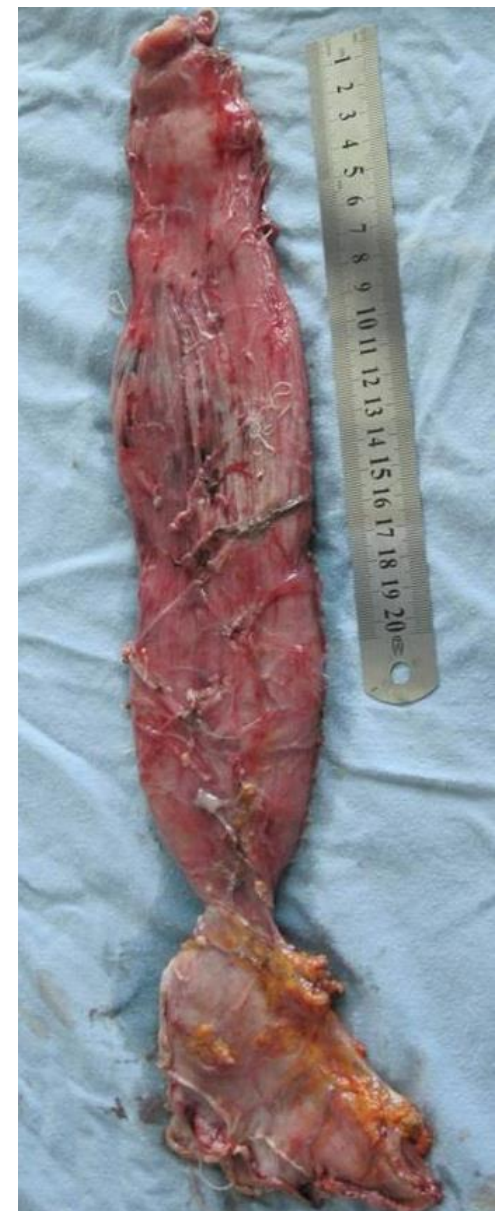

B

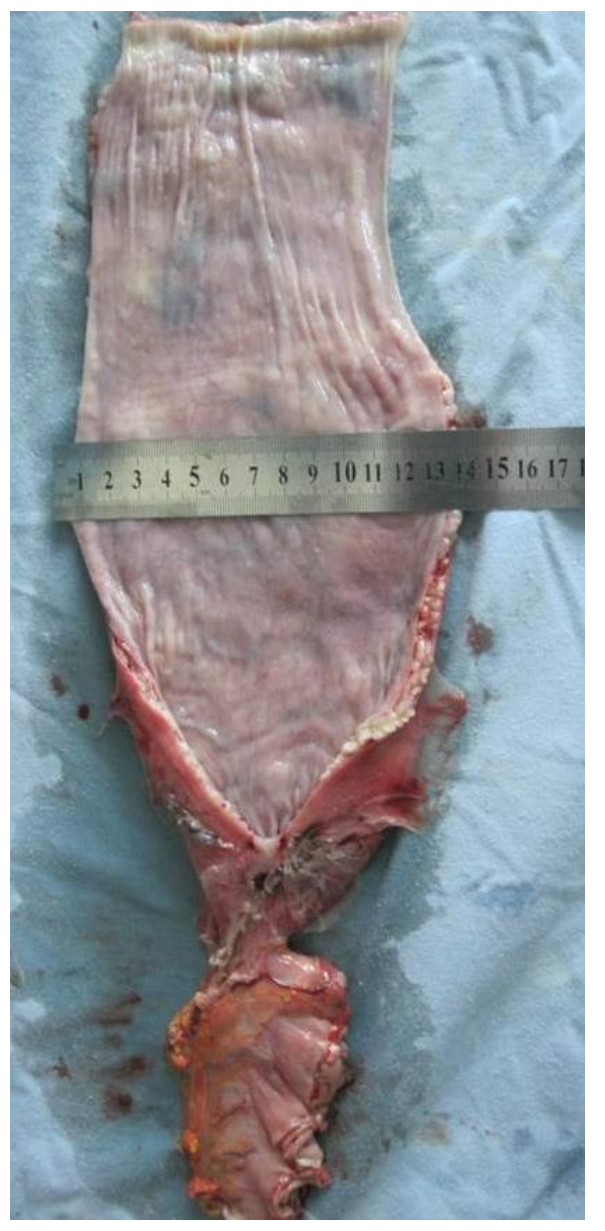

Figure 4. The extracted macro-preparation. $A=$ The mobilized esophagus. $B=$ The extracted macro-preparation. 
Complications of the esophagus extirpation in patients with neglected stages of achalasia are divided into intraoperative, immediate and late postoperative complications. The difficulty of the esophagus extirpation in patients with neglected stages of achalasia is in the difficulty and danger of the esophagus mobilization through the abdomino-cervical approach which are caused by severe esophagectasia and periesophagitis. In this regard, we observed the following intraoperative complications: bleeding from the mediastinum in 5 (17.8\%) which was stopped intraoperatively by a mediastinal plugging; injury of the mediastinal pleura in 14 (50\%) which required additional drainage of the pleural cavities; injury of the left recurrent nerve in 4 (6.3\%) which caused a temporary loss of voice and a disorder of the swallowing act and which was normalized during the first 6 months after the operation against the background of therapy in the ENT specialists.

The following complications were observed in the immediate postoperative period: bronchopulmonary complications in 5 patients (17.8\%): pneumonia in 2 patients, exudative pleurisy in 3 patients and specific complications in 1 patient (3.6\%) had the esophagogastro-anastomosis failure.

All complications were stopped by conservative measures. No lethal outcomes were observed. All 28 patients were examined in the long-term period, in terms from 6 months to 20 years. Only in 2 cases (7.2\%) cicatricial narrowing of esophagogastrostomy was diagnosed which required repeated bougienage and dilatation courses with a good clinical effect.

\section{CONCLUSION}

The main treatment method for the patients with achalasia remains cardiodilation which belongs to the minimally invasive methods and allows ensuring adequate restoration of food patency. However, in patients with neglected stages its efficiency is significantly reduced, and the frequency of recurrent dysphagia is increased. In patients with neglected stages of achalasia when the peristaltic activity of the esophagus is completely lost severe esophagoectasia is developed, as well as S-shaped deformation of the esophagus and the cardia itself. The operation of choice for these patients is the esophagus extirpation with simultaneous gastroesophagoplasty and the formation of extracavitary esophagogastroanastomosis in the neck. Compliance with all principles of gastroesophagoplasty will minimize the risk of dangerous intraoperative and postoperative complications. Further control randomized trials and multicentric studies should be performed. Though the represented study is a single center results and control randomized trials and multicentric studies should be performed.

\section{DECLARATIONS}

\section{Acknowledgements}

This work was supported by "Republican Specialized Surgery Centre named after Academician V.Vakhidov", Tashkent. Uzbekistan.

\section{Authors' contributions}

All authors contributed equally to this work.

\section{Competing interests}

The authors declare that they have no competing interests.

\section{REFERENCES}

1. Allakhverdyan AS, Mazurin VS. Incomplete oblique posterior lateral fundoplication in esophagocardiomyotomy for achalasia. Thoracic and cardiovascular surgery. 2007; 6: 32-36.

2. Chernousov AF, Khorobrykh TV, Vetshev FP. Achalasia and cardiospasm - modern principles of treatment. Ann Surg. 2012; 3: 5-10. Chernousov AF, Khorobrykh TV, Vetshev FP, Melentiev AA, Osminin SV. Esophageal achalasia and cardiospasm-contemporary principles of treatment. Annals of Surgery. 2012;3:5-10. Google Scholar

3. Andersson $M$, Lundell $L$, Kostic $S$, Ruth $M$, Lonroth $H$, Kjellin A. et al. Evaluation of the response to treatment in patients with idiopathic achalasia by the timed barium esophagogram: results from a 
randomized clinical trial. Dis Esophagus 2009; 22: 264-73. (Google Scholar ; https://doi.org/10.1111/j.14422050.2008.00914.x)

4. Naumann DN, Zaman S, Daskalakis M, Nijjar R, Richardson M, Super P, Singhal R. Day surgery for achalasia cardia: Time for consensus? Ann R Coll Surg Engl. 2016 Feb; 98(2): 150-4. DOI: 10.1308/rcsann.2016.0 (Google Scholar; https://doi.org/10.1308/rcsann.2016.0063)

5. Muravev V.Yu., Burmistrov M.V, Ivanov A.I. Endoscopic treatment of achalasia. Endoscopy. 2013; 2: 2-6.

6. Campos GM, Vittinghoff E, Rabl C et al. Endoscopic and surgical treatments for achalasia. A systematic review and meta-analysis. Ann Surg, 2009. 249: 45-57. (Google Scholar ; https://doi.org/10.1097/SLA.obo13e31818e43ab)

7. Katada N., Sakuramoto S., Yamashita K., Shibata T., Moriya H., Kikuchi S., Watanabe M. Recent trends in the management of achalasia. Ann Thorac Cardiovasc Surg. 2012; 18(5): 420-8. (Search PubMed ; https://doi.org/10.5761/atcs.ra.12.01949) 